\title{
Quantifying the Interest Rate Risk of Banks: Assumptions Do Matter
}

\section{Oliver Entrop}

Ingolstadt School of Management, Catholic University of Eichstätt-Ingolstadt, Auf der Schanz 49, D-85049 Ingolstadt, Germany

E-mail: oliver.entrop@ku-eichstaett.de

\section{Marco Wilkens}

Ingolstadt School of Management, Catholic University of Eichstätt-Ingolstadt, Auf der Schanz 49, D-85049 Ingolstadt, Germany

E-mail:marco.wilkens@ku-eichstaett.de

\section{Alexander Zeisler}

Ingolstadt School of Management, Catholic University of Eichstätt-Ingolstadt, Auf der Schanz 49, D-85049 Ingolstadt, Germany, and Barclays Capital, London, UK

E-mail: alexander.zeisler@ku-eichstaett.de

\begin{abstract}
This paper analyses the robustness of the standardised framework proposed by the Basel Committee on Banking Supervision (2004b) to quantify the interest rate risk of banks. We generalise this framework and study the change in the estimated level of interest rate risk if the strict assumptions of the standardised framework are violated. Using data on the German universal banking system, we find that estimates of the interest rate risk are very sensitive to the framework's assumptions. We conclude that the results obtained using the standardised framework in its current specification should be treated with caution when used for supervisory and risk management purposes.
\end{abstract}

Keywords: interest rate risk, Basel Capital Accord, banking supervision, standardised interest rate shock

JEL classification: $G 18, G 21$

This paper represents the authors' personal opinions and does not necessarily reflect the views of Barclays Capital. We thank the Deutsche Bundesbank for providing the data. We are grateful to the participants at the EFMA Annual Meeting 2008, Athens, the SFA Annual Meeting 2008, Key West, and the Banking Workshop 2008 at the University of Münster. We especially thank Robert DeYoung, Martin Hibbeln, Gunther Löffler, Christoph Memmel, Andreas Pfingsten, Larry Wall and an anonymous referee for helpful comments and suggestions on an earlier draft of this paper. All remaining errors are our own. Correspondence: Oliver Entrop. 


\section{Introduction}

Interest rate risk, along with credit risk, is one of the crucial risks banks face. It naturally arises in the banking book from the basic banking business when banks act as asset transformers, i.e., they lend out long-term and refinance short-term. This causes a maturity mismatch between assets and liabilities, closely related to a repricing mismatch, and results in a duration gap that makes the economic value of banks sensitive to changes in the yield curve (see, e.g., Bhattacharya and Thakor, 1993). ${ }^{1}$ The US Savings and Loan Crisis of the 1980s, where more than 550 of the approximately 4,000 savings and loan institutions failed, is a well-known example where interest rate risk played an integral role (see, e.g., Federal Deposit Insurance Corporation, 1997).

Since it is a systematic risk, interest rate risk is especially important to the stability of the financial system. The new Basel Capital Accord (Basel II, see Basel Committee on Banking Supervision, 2004a) aims to strengthen the stability of the financial system and establishes detailed minimum mandatory capital requirements for credit risk and operational risk. However, there are no mandatory capital requirements for interest rate risk in the banking book. Instead, it is supervised under pillar 2 ('supervisory review process') of Basel II. In this context, the Basel Committee published principles for the management and supervision of interest rate risk (see Basel Committee on Banking Supervision, 2004b). Banking supervisors are advised to be especially attentive to those banks - called 'outlier banks' - whose economic value in relation to regulatory capital declines by more than $20 \%$ if a 'standardised interest rate shock' occurs. ${ }^{2}$ The Basel Committee on Banking Supervision (2004b) stresses that 'banks' internal measurement systems should, wherever possible, form the foundation of the supervisory authorities' measurement of, and response to, the level of interest rate risk'. Acknowledging that not all banks are able to adequately quantify their interest rate risk with advanced internal models, the Basel Committee provides a standardised framework as a possible model to obtain information on the interest rate risk in the banking book. ${ }^{3}$ This standardised framework has been implemented in the supervisory legislation in many countries, such as Germany (Bundesanstalt für Finanzdienstleistungsaufsicht, 2007). ${ }^{4}$

This paper aims to evaluate whether the Basel Committee's standardised framework is adequate and robust enough to assess the interest rate risk of banks. Although it is clear that a simple model will always lead to somewhat incorrect results, the issue is still critical to both banking supervisors and banks. If assumptions of the standardised framework turn out to be inadequate or too simplistic, banking supervisors might severely misjudge a bank's interest rate risk and thus react inappropriately. Additionally, this may give rise to poor bank-internal risk management decisions, as internal risk measurement systems are often based on ideas similar to the Committee's proposal. Hence, it is crucial for banking supervisors and banks to understand to what extent the

\footnotetext{
${ }^{1}$ Other sources of interest rate risk for banks are given by embedded options and different interest rate pass-through policies for asset and liability positions (basis risk), even if there is no repricing mismatch (e.g., Basel Committee on Banking Supervision, 2004b).

${ }^{2}$ See Section 2.1 for details.

${ }^{3}$ Basel II's treatment of interest rate risk in the banking book is clearly in the spirit of the rules for credit risk in which standardised and bank-internal (ratings-based) approaches also exist.

${ }^{4}$ Similar approaches have been applied for many years by national supervisory institutions such as the Federal Reserve (e.g., Houpt and Embersit, 1991).
} 
underlying assumptions can affect the model-implied level of interest rate risk. To the best of our knowledge, this paper provides the first robustness analysis for this kind of approach.

For this purpose, we develop and apply a generalisation of the Basel Committee's model to analyse the effects of different economically sensible assumptions on the number and boundaries of the time bands, the distribution of maturities within the time bands, amortisation rates, coupons, and the economic maturity of non-maturing deposits. To base our analysis on a realistic setting, we consider the interest rate risk of the aggregated German universal banking system, that is, a hypothetical bank that can be interpreted as an 'average German universal bank'. We make use of data provided by the Deutsche Bundesbank that is not publicly available. These contain regulatory data on on-balance-sheet positions of German banks; however, detailed information on the use of derivatives is not available. ${ }^{5}$

We find that estimates of the interest rate risk vary substantially depending on the model's assumptions. Banks such as the 'average German universal bank' can be easily identified as either a very risky outlier bank or a low-risk bank. We find certain assumptions to be more relevant than others. Furthermore, the influence of the assumptions depends on a bank's business model. For example, the assumption regarding the economic maturity of non-maturing deposits is of great relevance for the 'average German universal bank', and is generally more relevant for savings and cooperative banks than for private commercial banks. All in all, our analysis highlights the great dependence of the Basel Committee's framework on the model assumptions. Therefore, the results obtained using the standardised framework in its current specification should be treated with caution if employed for supervisory and risk management purposes.

The remainder of this paper is organised as follows. Section 2 presents the Basel Committee's standardised framework and generalises the model by relaxing the assumptions. Section 3 describes the data sources for our analysis. In Section 4 we estimate interest rate risk according to the suggestions of the Basel Committee. In Section 5 we apply the generalised model to analyse the impact of different economically relevant assumptions on the estimates to gain insight into the robustness of the Basel Committee's approach. Section 6 summarises the findings and offers conclusions.

\section{Model}

\subsection{Definition of interest rate risk}

The Basel Committee on Banking Supervision (2004b) points out that there are several possible ways to define and measure interest rate risk. For supervisory purposes, the Committee suggests estimating the level of interest rate risk for exposures in G10

\footnotetext{
${ }^{5}$ As a by-product of our analysis, by incorporating these data we also shed some light on the structure of interest rate risk of the German universal banking system ex derivatives. Although little is yet known about the interest rate risk in the German banking system, there are indications that the level of interest rate risk is comparatively high (e.g., Deutsche Bundesbank, 2006a). Entrop et al. (2008) analyse the determinants of the interest risk on the individual bank level. Note that disregarding derivatives in our analysis does not substantially affect our primary results. Incorporating derivatives would affect the estimated level of interest rate risk but the sensitivities to the assumptions on the on-balance-positions would remain essentially unchanged.
} 
currencies by the decline of a bank's economic value in relation to its regulatory capital following a standardised interest rate shock. This shock is given by an upward and downward 200 basis points parallel movement of the term structure. ${ }^{6}$ Approximating the interest rate sensitivity by the duration, we similarly define the interest rate risk as follows:

$$
I R R^{\text {bank }}=0.02 \frac{P V^{\text {bank }} M D^{\text {bank }}}{R C^{\text {bank }}},
$$

where $P V^{\text {bank }}$ denotes the present value of the bank portfolio (that is, the difference between the present value of interest rate-sensitive assets and liabilities, commonly referred to as 'net portfolio value', e.g., Office of Thrift Supervision, 2000), $M D^{\text {bank }}$ is its modified duration referred to as 'duration gap' (e.g., Toevs, 1982), and $R C^{\text {bank }}$ is the bank's regulatory capital.

In contrast to the risk measure proposed by the Basel Committee, which equals the absolute value of (1), the measure IRR ${ }^{\text {bank }}$ is monotone in the bank's duration gap, and can therefore become negative. This allows for a straightforward interpretation: for a bank with a positive duration gap, $I R R^{\text {bank }}$ refers to the loss (gain) of economic value in relation to its regulatory capital when interest rates increase (decrease) by 200 basis points. The opposite holds when the duration gap of the bank is negative.

\subsection{The Basel Committee's approach}

The Basel Committee on Banking Supervision (2004b) proposes a standardised framework for calculating the interest rate risk in the banking book. Comparable models are already applied by banking supervisors, such as the Economic Value Model (EVM) used by the Federal Reserve to quantify the interest rate risk of U.S. commercial banks (see Houpt and Embersit, 1991; Wright and Houpt, 1996; Sierra, 2004; Sierra and Yeager, 2004). Other similar models include Bennett et al. (1986), Patnaik and Shah (2004), and Entrop et al. (2008).

In line with these models, the Basel Committee suggests calculating the interest rate risk on the basis of time bands. ${ }^{7}$ These time bands show the outstanding amount of interest rate-sensitive assets and liabilities broken down by their remaining time to maturity (in the case of fixed-rate instruments) or repricing period (in the case of floating-rate instruments). The Basel Committee proposes the following time bands: i) up to 1 month, ii) 1 to 3 months, iii) 3 to 6 months, iv) 6 to 12 months, v) 1 to 2 years, vi) 2 to 3 years, vii) 3 to 4 years, viii) 4 to 5 years, ix) 5 to 7 years, x) 7 to 10 years, xi) 10 to 15 years, xii) 15 to 20 years, and xiii) over 20 years. For some positions, such as non-maturing deposits, the behavioural (economic) maturity differs from the legal maturity. The Basel Committee suggests that these positions be slotted into the time bands according to the guidance of national supervisors; however, the

\footnotetext{
${ }^{6}$ Alternatively, the interest rate shock may be based on the 1st and 99th percentile of the yearly interest rate change.

${ }^{7}$ There are also numerous models and papers that analyse the interest rate sensitivity of (exchange-traded) banks based on stock returns rather than on accounting-based regulatory data. This approach was pioneered by Stone (1974) and has recently been applied by several authors to European financial corporations, including Oertmann et al. (2000) and Czaja et al. (2009a, 2009b). However, because in many countries (including Germany) most banks are not listed, this approach to analysing the interest rate risk is not universally applicable for supervisory purposes.
} 
assumed economic maturity of non-maturing deposits should be no longer than 5 years. Interest rate derivatives such as swaps and futures held in the banking book are to be duplicated by basic instruments - like zero, fixed- or floating-rate bonds - that can then be assigned to the respective time bands.

In the next step, a modified duration is assigned to each time band that corresponds to a position situated in the middle of the time band and that yields $5 \%$. The present values of the bank's assets and liabilities are approximated by the book value. ${ }^{8}$ The durations are weighted with the outstanding amount of the time bands and summed up in order to calculate the risk measure (1).

\subsection{Generalisation of the Basel Committee's approach}

The framework of the Basel Committee presented in Section 2.2 is intuitive but the assumptions are rather strict. Therefore, we generalise the framework to analyse the effect of the model's assumptions on the estimation of the interest rate risk. We allow for different numbers and boundaries of time bands as well as for different distributions of the business within the time bands, different amortisation rates and different coupons.

The actual information available to banking supervisors or external analysts differs between countries. The generalised model can capture current and potentially future reporting practices in various countries, including the USA or Germany. We assume that banks report the outstanding amount for each interest rate-sensitive on-balancesheet position broken down by the remaining time to maturity or repricing period, respectively. For each position pos there are $\left|N^{p o s}\right|$ time bands available: $R T M^{p o s, n}$ with $n \in N^{p o s}$ denotes the amount of position pos with a remaining time to maturity within the time band $\left(h_{\text {lower }}^{\text {pos },}, h_{\text {upper }}^{\text {pos,n }}\right.$.

The 'location parameter' $l$ determines the distribution of the remaining time to maturity $T$ of the business within a time band: ${ }^{9}$

$$
T=h_{\text {lower }}^{\text {pos }, n}+l\left(h_{\text {upper }}^{\text {pos, }}-h_{\text {lower }}^{\text {pos },}\right) \quad \text { with } 0 \leq l \leq 1 .
$$

Values of $l$ between 0 and 1 imply a concentration inside the time band, whereas the 'extreme' (and certainly unlikely) cases where $l=0$ and $l=1$ imply that the complete outstanding amount is in the lower or upper end of the time band. Due to the linear approximation of the interest rate sensitivity by the modified duration, any distribution of maturities within a time band is equivalent to a concentration of all business at a certain point in time.

The amortisation rate $a$ is defined as the continuously compounded rate of business that is redeemed before maturity, $c$ refers to the continuously compounded coupon rate and $r$ denotes the continuously compounded market interest rate.

The calculation of the present value $P V^{p o s, n}(l, a, c, r)$ and the modified duration $M D^{p o s, n}(l, a, c, r)$ of the business in a certain time band is straightforward (see

\footnotetext{
${ }^{8}$ The present value of fixed-rate instruments generally equals its book value if and only if the coupon rate equals the discount rate, that is, the adequate market interest rate (see the Appendix). However, business that is contracted with customers on the asset side (liability side) can be expected to yield a higher (lower) coupon than the market interest rate, resulting in a present value higher (lower) than the book value.

${ }^{9}$ For simplicity, we omit indices and superscripts when considering $T$. Although we define time bands $\left(h_{\text {lower }}^{\text {pos },}, h_{\text {upper }}^{\text {pos },}\right]$ to be left open, we allow for $l=0$ here as $h_{\text {lower }}^{\text {pos }, n}$ represents the infimum of all possible maturities within the time band.
} 
Appendix): ${ }^{10}$

$$
\begin{gathered}
P V^{p o s, n}(l, a, c, r)=\left(\frac{c+a}{r+a}-\frac{c+a}{r+a} e^{-(a+r) T}+e^{-(a+r) T}\right) R T M^{p o s, n} \\
M D^{p o s . n}(l, a, c, r)=\frac{1}{a+r}+\frac{1+(c-r) T}{c-r-(a+c) e^{(a+r) T}}
\end{gathered}
$$

where $T$ is defined according to (2).

The present values and the modified durations of the business within single time bands can be aggregated to the net portfolio value and its duration gap as follows:

$$
\begin{aligned}
& P V^{\text {bank }}=\sum_{\substack{p o s \in P O S^{A} \\
n \in N^{\text {pos }}}} P V^{\text {pos }, n}(\cdot)-\sum_{\substack{p o s \in P O S^{L} \\
n \in N^{\text {pos }}}} P V^{\text {pos }, n}(\cdot), \\
& \frac{\sum_{\substack{p o s \in P O S^{A} \\
n \in N^{p o s}}} M D^{p o s, n}(\cdot) P V^{p o s, n}(\cdot)-\sum_{\substack{p o s \in P O S^{L} \\
n \in N^{p o s}}} M D^{p o s, n}(\cdot) P V^{p o s, n}(\cdot)}{P V^{b a n k}}
\end{aligned}
$$

where $P O S^{A}\left(P O S^{L}\right)$ refers to the set of all asset (liability) positions. ${ }^{11}$ These values in turn determine the level of interest rate risk according to (1).

Given this generalisation, the standardised framework proposed by the Basel Committee on Banking Supervision (2004b) and presented as in Section 2.2 is a special case that can be obtained by setting $l=0.5, c=r=0.05$ and $a=0$. In this case, the business is assumed to be non-amortising and concentrated in the middle of the time bands. It exhibits a 5\% yield and its present value is equal to its book value.

\section{Data}

To assess the impact that different model assumptions have on the interest rate risk of banks with reasonably sized interest rate-sensitive business, we use regulatory data for the German universal banking system (private commercial banks, state-owned savings banks and member-owned cooperative banks) as of December 2005. All data are provided by the Deutsche Bundesbank. We employ a representative 'average German universal bank' corresponding to the German universal banking system in the following analysis. ${ }^{12}$ We include three interest rate-sensitive asset positions ('interbank loans', 'customer loans' and 'debt securities held') and four interest rate-sensitive liability positions ('interbank liabilities', 'customer liabilities', 'debt securities issued' and 'savings deposits'). These positions represent $97.0 \%$ and $92.8 \%$ of all assets and liabilities, respectively. As detailed information on interest rate derivatives and other

\footnotetext{
${ }^{10}$ In line with the suggestions of the Basel Committee on Banking Supervision (2004b) we assume default-free cash flows and apply the 'standard' modified duration, acknowledging that the duration of a defaultable cash flow may differ from the duration of a respective default-free cash flow (e.g., Jacoby and Roberts, 2003).

${ }^{11}$ If $P V^{\text {bank }}=0$, the modified duration (6) is not well defined. The interest rate risk measure (1) is then given by $I R R^{\text {bank }}=0.02$ numerator of (6) $/ R C^{\text {bank }}$.

${ }^{12}$ This 'average German universal bank' is created by aggregating each position across $92.4 \%$ $(1,785)$ of all German universal banks $(1,932)$. Banks with incomplete data are excluded.
} 
off-balance-sheet positions in the banking book is not available, we do not include these instruments in the analysis.

The time bands representing a breakdown by remaining time to maturity that are currently available to German banking supervisors are rather broad. Most asset and liability positions are broken down into only four time bands: i) up to 3 months, ii) 3 to 12 months, iii) 1 to 5 years and iv) more than 5 years. In contrast, to estimate the interest rate risk according to the Basel Committee and to assess the impact of the number and the boundaries of available time bands, we need more detailed sets of time bands. To obtain these values we make use of the Time Series Accounting-Based Model (TAM) recently proposed by Entrop et al. (2008). The TAM integrates time series of different accounting-based regulatory data sources to estimate the monthly maturity structure of a bank's assets and liabilities. ${ }^{13}$ Based on this detailed structure, we can synthetically generate the amount of business that occurs within each time band in our analysis by simply aggregating the respective monthly amounts.

To calculate the measure of interest rate risk (1), we use regulatory capital ('own funds') from Principle I.

\section{Interest Rate Risk According to the Basel Committee and Reference Scenario}

In this section we analyse the model suggested by the Basel Committee on Banking Supervision (2004b). Accordingly, we assume that the complete outstanding amount of a position within a time band is concentrated in the middle $(l=0.5)$, bears a coupon of $5 \%(c=0.05)$ and is not amortised $(a=0) .{ }^{14}$ Further, we assume that the market interest rate equals the coupon $(r=c=0.05)$.

Finally, we must assign a certain economic maturity, or equivalently, an interest rate sensitivity, to savings deposits as the most important kind of non-maturing deposits for German banks. Although they are de jure short-term liabilities, they can have rather high interest rate sensitivity since the deposit rates and the volume of deposits are sticky. This yields a duration higher than that of other short-term instruments. Many papers, including Hutchison and Pennacchi (1996), Jarrow and van Deventer (1998), O'Brien

${ }^{13}$ The basic idea of the TAM is as follows. When considering time bands only at a single point in time, we have to make an assumption regarding the distribution of maturities within a time band, such as the assumption of a concentration in the middle of the time band. If we look at time bands at several points in time, we have more information as the time bands are not independent over time; business migrates between the time bands over time. Entrop et al. (2008) show that this additional (time series) information can be used to achieve more reasonable estimates of the distributions of maturities within the time bands, and thus better estimates of interest rate risk than is possible with standard approaches. To estimate the monthly maturity structure of the assets and liabilities based on the TAM as specified by Entrop et al. (2008), we also use German regulatory and accounting data from the time period of January 1999 to December 2005 - the data schedule pursuant to the auditor's report ('Sonderdatenkatalog') that is reported yearly and the monthly balance sheet statistics ('Monatliche Bilanzstatistik'). As the TAM is not the focus of this paper, but is rather simply a tool to obtain reasonable realistic maturity structures for our analysis, a detailed description of the TAM is beyond the scope of this paper and we refer the reader to Entrop et al. (2008) for details.

${ }^{14}$ The longest time band available to the Deutsche Bundesbank reports the outstanding amount of more than 5 years. We therefore cannot reliably estimate the long-term maturity structure in detail. Hence, we assume a maximum possible maturity of 10 years. 
Table 1

Reference scenario according to the Basel Committee's standardised framework.

This table shows the time bands proposed by the standardised framework of the Basel Committee on Banking Supervision (2004b). The respective modified durations are shown assuming non-amortising $(a=0)$ positions concentrated in the middle of the time bands $(l=0.5)$, a coupon rate of $5 \%$ $(c=0.05)$ and a market interest rate of $5 \%(r=0.05)$. All rates are continuously compounded. The modified duration of savings deposits is set to 2.5. Finally, the absolute (in EUR $10^{11}$ ) and relative (in \%) outstanding amounts of assets and liabilities, aggregated over all German universal banks and positions in our dataset, and the net position in the time bands are shown. These are obtained by estimating the Time Series Accounting-Based Model (TAM) as specified by Entrop et al. (2008) for a hypothetical bank corresponding to the aggregated German universal banking system. We only take possible maturities of up to 10 years into account, thus omitting the time bands of 10 to 15 years, 15 to 20 years, and of over 20 years (see Footnote 14).

\begin{tabular}{|c|c|c|c|c|c|c|}
\hline \multirow[b]{2}{*}{ Time band } & \multirow{2}{*}{$\begin{array}{c}\text { Modified } \\
\text { duration }\end{array}$} & \multicolumn{2}{|c|}{ Assets } & \multicolumn{2}{|c|}{ Liabilities } & \multirow{2}{*}{$\frac{\text { Net position }}{\left(\text { EUR } 10^{11}\right)}$} \\
\hline & & $\left(\right.$ EUR $\left.10^{11}\right)$ & $\%$ & $($ EUR 10 11$)$ & $\%$ & \\
\hline Up to 1 month & 0.04 & 11.10 & 22.79 & 17.49 & 37.52 & -6.39 \\
\hline 1 to 3 months & 0.17 & 7.62 & 15.64 & 6.58 & 14.11 & 1.04 \\
\hline 3 to 6 months & 0.37 & 1.61 & 3.30 & 1.33 & 2.84 & 0.28 \\
\hline 6 to 12 months & 0.74 & 3.40 & 6.97 & 1.64 & 3.52 & 1.76 \\
\hline 1 to 2 years & 1.45 & 3.06 & 6.29 & 2.62 & 5.61 & 0.45 \\
\hline 2 to 3 years & 2.35 & 2.44 & 5.01 & 2.49 & 5.34 & -0.05 \\
\hline 3 to 4 years & 3.21 & 3.96 & 8.13 & 2.49 & 5.34 & 1.47 \\
\hline 4 to 5 years & 4.03 & 2.55 & 5.23 & 1.08 & 2.31 & 1.47 \\
\hline 5 to 7 years & 5.18 & 8.93 & 18.33 & 3.76 & 8.07 & 5.17 \\
\hline 7 to 10 years & 6.92 & 4.04 & 8.30 & 1.78 & 3.82 & 2.26 \\
\hline Savings deposits & 2.50 & - & - & 5.37 & 11.52 & -5.37 \\
\hline Sum & - & 48.70 & 100 & 46.61 & 100 & 2.09 \\
\hline
\end{tabular}

(2000), Kalkbrener and Willing (2004) and Dewachter et al. (2006) propose and apply different models for analysing the value and interest rate risk of non-maturity products. Unfortunately, as recently stressed by the Basel Committee on Banking Supervision (2008), there is still no evidence regarding which model is best. As described in Section 2.2, the Basel Committee suggests slotting non-maturing deposits into the time bands; however, the assumed economic maturity should be no longer than 5 years. In line with Houpt and Embersit (1991), we therefore initially set the modified duration of the savings deposits to 2.5 years.

Table 1 shows the time bands suggested by the Basel Committee and the respective modified durations, ${ }^{15}$ as well as the outstanding amount of assets, liabilities and net positions obtained by the TAM. It shows that there are more (less) long-term (shortterm) assets than respective liabilities, indicating that German banks typically still act as maturity transformers (see, also, Schmidt et al., 1999). This results in a positive duration gap, which makes banks sensitive to rising interest rates. In the following, this specification in Table 1 (based on the Basel II time bands and the Basel II assumptions that $l=0.5, c=r=0.05$, and $a=0$ ) will be referred to as the 'reference scenario'.

${ }^{15}$ The modified durations differ slightly from those in Basel Committee on Banking Supervision (2004b) as our analysis is based on continuously compounded rates (see Section 2.3). 
For the reference scenario we calculate a level of interest rate risk of $30.9 \%$. This means that the aggregated German universal banking system would lose (gain) $30.9 \%$ of its economic value relative to its own funds if interest rates increase (decrease) by 200 basis points. However, this number must be interpreted with caution due to the impact of the simplifying assumptions whose effects we analyse in the remainder of this paper. Furthermore, interest rate derivatives are omitted. These can be assumed, on average, to reduce the interest rate risk of single banks (Schrand, 1997; Purnanandam, 2007), whereas the impact on the banking system as a whole is still unknown.

Analysing the impact of different assumptions on the modified duration of savings deposits is straightforward, since the interest rate sensitivity of cash flows is additive. By dividing the bank portfolio into the on-balance-sheet positions excluding the savings deposits, and the savings deposits, the interest rate risk measure (1) can be represented as follows:

$$
I R R^{\text {bank }}=I R R_{\text {ex savings }}^{\text {bank }}-0.02 \frac{P V^{\text {savings }} M D^{\text {savings }}}{R C^{\text {bank }}},
$$

where $I R R_{\text {ex savings }}^{\text {bank }}$ denotes the interest rate risk of all positions except savings deposits, $P V^{\text {savings }}$ is the economic value of savings deposits, ${ }^{16}$ and $M D^{\text {savings }}$ is the modified duration assigned to savings deposits.

As the amount of savings deposits in the aggregated German banking system is about twice as high as the regulatory capital, (7) implies that increasing the modified duration $M D^{\text {savings }}$ by one year decreases the interest rate risk measure IRR ${ }^{\text {bank }}$ by 4 percentage points. Given a range of 0 to 5 years for the economic maturity (as proposed by the Basel Committee), estimates for interest rate risk can vary by up to 20 percentage points.

This has an interesting implication. Let us consider a bank that has savings deposits and regulatory capital in the same relative amount as the German banking system and an interest rate risk $I R R_{\text {ex savings }}^{\text {bank }}$ of $20 \%$, ignoring savings deposits. Taking the savings deposits into account, the bank could be regarded as either an outlier bank (assigning no interest rate sensitivity to savings deposits) or as a no-risk bank (assigning a modified duration of 5 years to savings deposits).

Coming back to the reference scenario, the estimated interest rate risk decreases from $30.9 \%$ to $20.9 \%$ when the modified duration of savings deposits is adjusted from 2.5 to 5 years, and increases to $40.9 \%$ when the modified duration is set to 0 years. This means that, depending on the assumptions regarding the economic maturity of savings deposits, the aggregated German universal banking system would lose (gain) between $40.9 \%$ and $20.9 \%$ of its economic value in relation to its own funds when interest rates increase (decrease) by 200 basis points.

This effect is even stronger if we consider banks that have a higher savings-depositsto-regulatory-capital ratio than the average German bank. Indeed, the German universal banks differ depending on their banking group, their business model (Schmidt and Tyrell, 2004) and the relevance of their interest bearing business (Deutsche Bundesbank, 2006b). For example, the respective ratios are higher than 4 for average savings and cooperative banks. This implies a possible range of the quantified interest rate risk of more than 40 percentage points.

\footnotetext{
${ }^{16}$ In line with the accounting-based models proposed in the literature and the earlier assumptions, we approximate the present value of savings deposits by their book value. Since the book value is usually higher than the present value (e.g., Hutchison and Pennacchi, 1996), the impact is overestimated.
} 
The above considerations show that estimates of interest rate risk vary substantially depending on the assumptions concerning the economic maturity of the savings deposits. Thus, even within the framework suggested by the Basel Committee on Banking Supervision (2004b), banks and banking supervisors have significant opportunities to influence the quantified interest rate risk. In the following section we analyse how estimates of the interest rate risk vary when we relax the economically relevant assumptions set by the Basel Committee on Banking Supervision (2004b).

\section{Sensitivity of the results to different assumptions}

\subsection{Distribution of maturities within the time bands}

In this section we analyse problems arising from calculations that are not based on the detailed cash flow structure but on time bands, making it necessary to assume a certain distribution of maturities within the time bands. The Basel Committee's model assumes that the total outstanding amount is concentrated in the middle of the time bands. This assumption is in line with the methodology of the Federal Reserve (e.g., Houpt and Embersit, 1991) and others (e.g., Bennett et al., 1986; Patnaik and Shah, 2004). However, this is not necessarily a true or a plausible approximation.

Let us consider a time band $\left(h_{\text {lower }}^{\text {pos },}, h_{\text {upper }}^{\text {pos, }}\right]$ that includes a total outstanding amount of 1 and let the distribution of maturities within this time band be given by the distribution function $F(t)$. Under the Basel Committee's assumptions that $a=0$ and $r=c=0.05$, the 'correct' modified duration for this time band, based on (13) from the Appendix, is:

$$
\frac{1}{r} \int_{h_{\text {lower }}^{\text {pos, }}}^{h_{\text {upper }}^{\text {pos } n}}\left(1-e^{-r t}\right) d F(t)
$$

Any distribution $F$ of maturities within the time band is equivalent to a concentration at a certain point in the time band represented by the location parameter $l_{F}$ as a solution of:

$$
\frac{1}{r} \int_{h_{\text {lower }}^{\text {pos }, n}}^{h_{\text {upper }}^{\text {pos,n }}}\left(1-e^{-r t}\right) d F(t)=\frac{1}{r}\left(1-e^{-r\left(h_{\text {lower }}^{\text {pos, } n}+l_{F}\left(h_{\text {upper }}^{\text {pos }, n}-h_{\text {lower }}^{\text {pos, } n}\right)\right)}\right),
$$

where the left hand side is the 'correct' modified duration of the time band and the right hand side is the modified duration for a concentration at $T=h_{\text {lower }}^{\text {pos } n}+l_{F}\left(h_{\text {upper }}^{\text {pos,n }}\right.$ $h_{\text {lower }}^{\text {pos } n}$.

If, for example, a bank only continuously conducts business with maturity $h_{\text {upper }}^{\text {pos, }}$, the resulting distribution of maturities in the time band $\left(h_{\text {lower }}^{\text {pos }, n}, h_{\text {upper }}^{\text {pos }, n}\right.$ is a uniform distribution; that is, $F(t)=\left(t-h_{\text {lower }}^{\text {pos }, n}\right) /\left(h_{\text {upper }}^{\text {pos }, n}-h_{\text {lower }}^{\text {pos },}\right)$ over $\left(h_{\text {lower }}^{\text {pos }, n}, h_{\text {upper }}^{\text {pos },}\right.$. Evaluating (9) for the exemplary time band $(4,5]$ results in a location parameter $l_{F}=0.4979$, which is very close to the Committee's assumption of 0.5 . In contrast, if, for example, new business is equally distributed over the time band, the final distribution of maturities within the time band equals a triangular distribution with mode $h_{\text {lower }}^{\text {pos }, n}$, i.e., $F(t)=$ $1-\left(h_{\text {upper }}^{\text {pos, }}-t\right)^{2} /\left(h_{\text {upper }}^{\text {pos, }}-h_{\text {lower }}^{\text {pos }, n}\right)^{2}$. This implies an equivalent location parameter $l_{F}=$ 0.3319 , which is much smaller than $0.5 .^{17}$

${ }^{17}$ In the analysed cases of a uniform or triangular distribution, the equivalent location parameter $l_{F}$ does not change much if Basel II time bands other than $(4,5]$ are considered. 


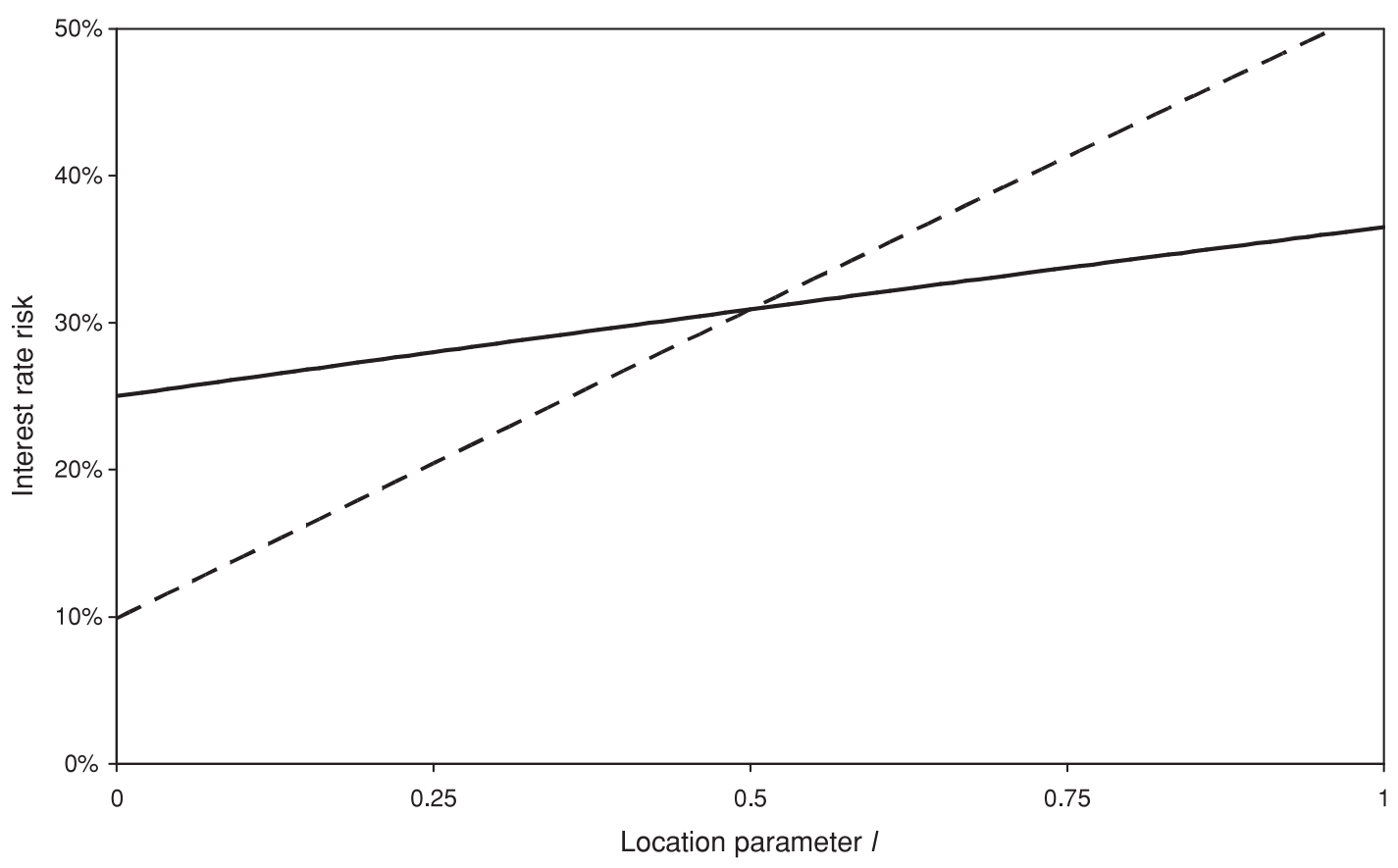

Fig. 1. Impact of the distribution of maturities within the time bands.

This figure shows the impact that different assumptions regarding the distribution of maturities within the time bands have on the estimates of interest rate risk. The location parameter $l$ is defined according to (2). It is not relevant for savings deposits because a modified duration (here 2.5) is directly assigned to them. The solid line illustrates the case when assets and liabilities are situated on the same side of the time bands. The dashed line represents the case when assets and liabilities are situated on opposite sides of the time bands ( $l^{\text {liabilities }}=1-l^{\text {assets }}$ with $l^{\text {assets }}=l$ ). The remaining model parameters are specified according to the reference scenario as described in Section 4, i.e., the Basel II time bands are used and the coupon and amortisation rate are set to $c=r=0.05$ and $a=0$.

As there are no data available concerning the distribution function $F$ for real banks, we cannot judge their 'correct' location parameters. However, it is clear that the 'correct' location parameter for single banks will certainly differ from 0.5 , sometimes significantly. To analyse whether different distributions of maturities within the time bands can have a substantial impact on the estimated level of interest rate risk, we calculate the interest rate risk while varying the location parameter $l$ as defined in (2), and holding the remaining parameters as specified in the reference scenario described in Section 4, that is, $c=r=0.05, a=0$ and the Basel II time bands from Table 1. Note that the location parameter is not relevant for savings deposits as a modified duration is directly assigned to them. Figure 1 shows the results. The solid line signifies the case where both assets and liabilities are located on the same side of the time bands. The dashed line refers to the case where assets and liabilities are located on opposite sides, that is, $l^{\text {liabilities }}=1-l^{\text {assets }}$, which we include for the sake of completeness. The reference scenario is represented by $l=0.5$, resulting in an interest rate risk of $30.9 \%$ as shown in Section 4.

The solid line has some interesting implications. First, the further the business is assumed to be concentrated in the lower ends of the time bands, the lower the implied level of interest rate risk is. This is plausible because there is more interest rate-sensitive business within the time bands on the asset side than on the liability side ex savings deposits (see Table 1). Furthermore, the assets are more concentrated in the long-term time bands that have a broader range and are, consequently, more affected by different $l$. 
Second, depending on the assumptions, the estimates of the interest rate risk vary by up to 11 percentage points. Since the Basel Committee on Banking Supervision (2004b) refers to an outlier bank as a bank with a level of interest rate risk of $20 \%$ or more, the range of 11 percentage points is obviously quite large so as to distinguish outlier banks from non-outlier banks. As is expected, the level of interest rate risk varies even more when assets and liabilities are concentrated on opposite sides of the time bands. In this extreme case, the model-implied interest rate risk varies as highly as 42 percentage points. However, values close to such extreme cases are extremely unlikely.

On the whole, our analysis underscores the importance of correctly assuming the maturities within the time bands in estimating the interest rate risk of banks. If a bank's business is not concentrated in the middle of the time bands, applying the standardised framework can result in highly biased estimates of the level of interest rate risk. This bias will, ceteris paribus, be larger the more the bank's 'true' location parameter differs from 0.5.

\subsection{Number and boundaries of the time bands}

The Basel Committee on Banking Supervision (2004b) proposes a reporting framework that is intended to be a guideline for national supervisors. However, the actual reported number of time bands differs between countries. We therefore also examine whether the number and boundaries of the time bands can affect the model results substantially. Accordingly, we repeat the analysis in Section 5.1 for different sets of time bands. First, we use the time bands available to the Deutsche Bundesbank (which are very broad) as described in Section 3. Second, we use the reporting framework suggested by the Basel Committee on Banking Supervision (2004b) (see Table 1). Third, we consider semiannual and finally monthly time bands. ${ }^{18}$ Figure 2 shows the results in dependence on the location parameter $l$.

Figure 2 implies that a large number of time bands of equal length are preferable to a smaller number of time bands. This is clear because the sensitivity of the level of interest rate risk to the location of the business within the time bands is greater for broader time bands. This effect is especially pronounced for banks that have more longterm assets than long-term liabilities (as in our case, see Table 1) in combination with reporting frameworks such as the German framework and the Committee's framework, which have broader time bands for longer maturities. Assuming actual German reporting practices, the estimates of the interest rate risk may vary by up to 28 percentage points. As shown in Section 5.1, for the Committee's proposal they may vary by up to 11 percentage points in the extreme cases. Instead, the estimates are nearly unaffected by the location parameter when semi-annual and monthly time bands are considered.

We also see that the results can vary substantially between the different reporting practices for given small or large location parameters. This strongly illustrates the need for a consensus among national reporting practices; otherwise the level of interest rate risk cannot be compared across countries. Of course, the identification of outlier banks in different countries should not depend on the national reporting practices.

\subsection{Amortisation payments}

We can expect that parts of the business are amortised before the maturity date. Since amortisation payments are primarily on the asset side, higher amortisation rates should

\footnotetext{
${ }^{18}$ As described in Section 3, we apply the TAM to synthetically create the respective time bands from the Bundesbank data.
} 


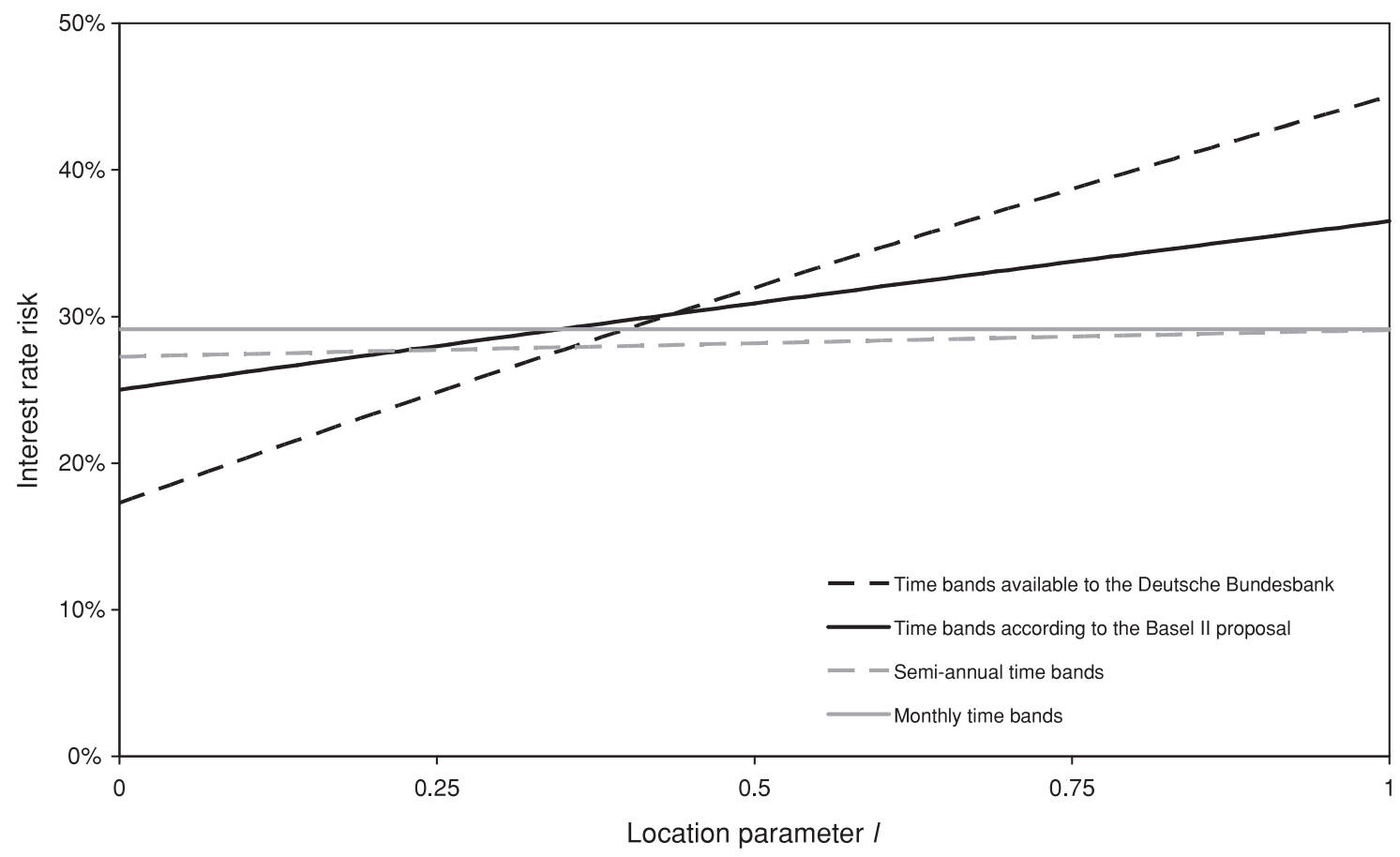

Fig. 2. Impact of the reporting framework.

This figure shows the impact of different reporting frameworks for different assumptions regarding the location $l$ of the business within the time bands on the estimates of the interest rate risk. The location parameter $l$ is defined according to (2). It is not relevant for savings deposits, because a modified duration (here 2.5) is directly assigned to them. Four sets of time bands are considered: i) the actual German reporting practice, which contains a breakdown into 4 time bands; ii) the reporting framework according to the Basel Committee on Banking Supervision (2004b); iii) semi-annual time bands; and iv) monthly time bands as obtained by the TAM. The remaining model parameters are specified according to the reference scenario as described in Section 4, i.e., the coupon and amortisation rate are set to $c=r=0.05$ and $a=0$.

result in the bank having a lower interest rate risk measure. In this section we analyse whether different assumptions regarding the amortisation rate of customer loans have a substantial impact on the estimates of the interest rate risk. Figure 3 shows the results for 5 different distributions of maturities within the time bands.

Obviously, varying (but still economically reasonable) amortisation rates can change the implied interest rate risk substantially. For example, for the Basel Committee's assumption $l=0.5$, an amortisation rate of $25 \%$ for the customer loans decreases the level of interest rate risk from $30.9 \%$ (reference scenario, $a=0$ ) to $9.0 \%$. The higher the amortisation rate, the lower the interest rate risk measure. The influence of different amortisation rates is lower (higher) for smaller (larger) maturities. That is, more business is assumed to be concentrated in the short (long) end of the time bands. For example, for a concentration at the short end of the time bands $(l=0)$ we obtain estimates for the level of interest rate risk of $25.0 \%$ to $8.1 \%$, a range of about 17 percentage points. In contrast, if the business is assumed to be concentrated at the long end of the time bands $(l=1)$, we obtain estimates of $36.5 \%$ to $9.4 \%$, a difference of about 27 percentage points. For realistic location parameters between 0 and 1, the possible range of the interest risk lies between these values. This analysis shows that neglecting amortisation payments can result in significant misestimation of a bank's interest rate risk, independent of the assumed location parameter. 


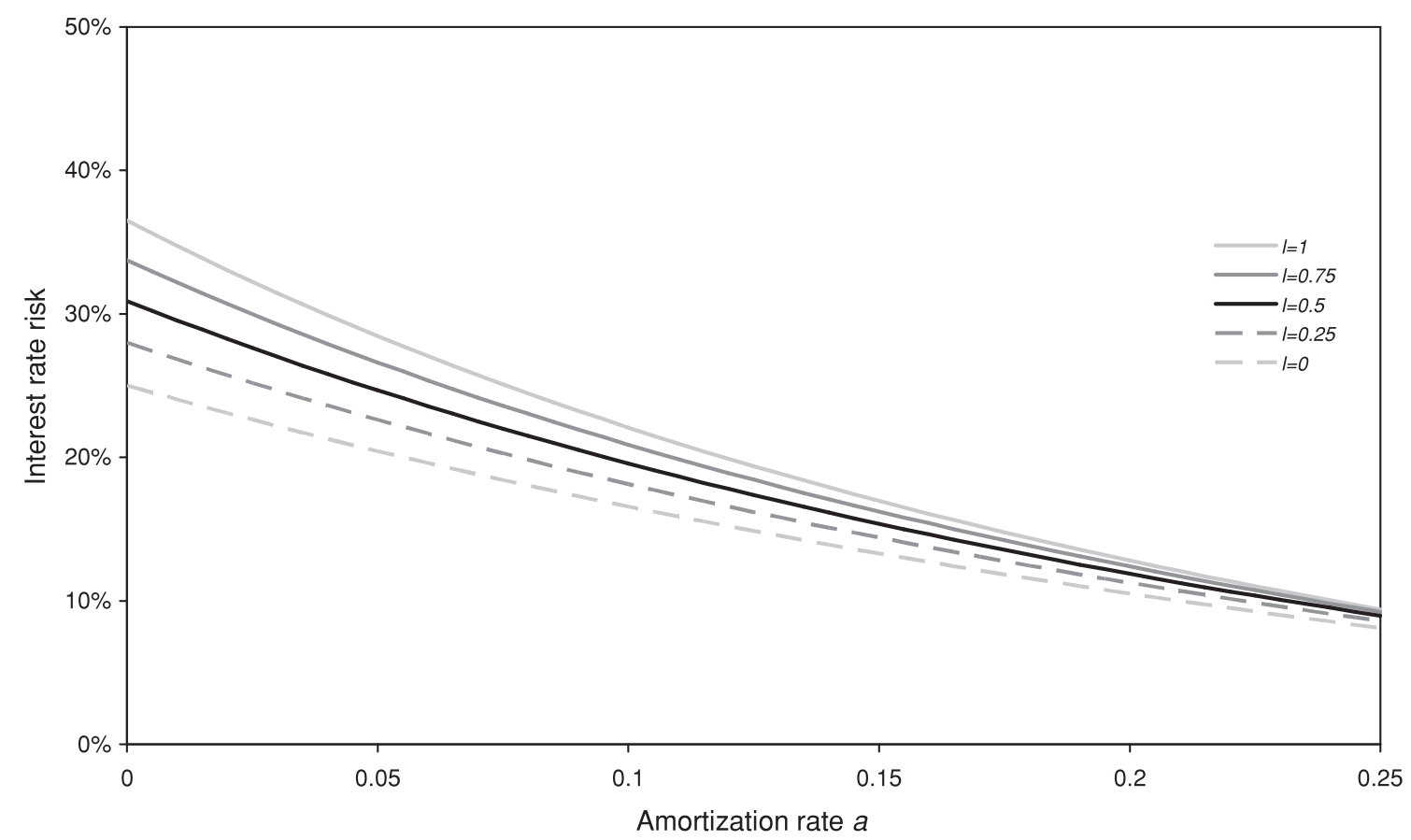

Fig. 3. Impact of the amortisation rate.

This figure shows the impact that different assumptions regarding the amortisation rate $a$ of customer loans have on the estimated interest rate risk for different location parameters $l$ of the business within the time bands. The location parameter $l$ is defined according to (2). It is not relevant for savings deposits, because a modified duration (here 2.5) is directly assigned to them. The remaining model parameters are specified according to the reference scenario as described in Section 4, i.e., the Basel II time bands are used and the coupon rate is set to $c=r=0.05$.

\subsection{Coupon payments}

The standardised framework assumes coupons and market interest rates to be equal. In reality, banks charge a higher interest rate for customer business on the asset side and pay less interest for customer business on the liability side, for example due to market power (Hutchison and Pennacchi, 1996). A coupon higher (lower) than the market interest rate, however, results in the higher (lower) interest rate risk of a position, since the coupon payments are also sensitive to changing interest rates. Hence, the interest rate risk measure should increase with a higher spread between coupons and market interest rates as the interest rate sensitivity of the asset side increases, whereas the sensitivity of the liability side decreases. However, it is unclear whether the impact is substantial. To analyse this effect, we vary the spread between the coupon rate $c$ and the market interest rate $r$ for customer loans and customer liabilities. Figure 4 shows the results.

As expected, the model-implied level of interest rate risk increases monotonically as the spread increases. Assuming a spread of 3\% yields an interest rate risk of $35.9 \%$; the estimates differ from the reference scenario $(c=r)$ by about 5 percentage points. Since the impact of assumptions on the coupon is higher for positions with a higher maturity, the estimates of interest rate risk are affected more if business is concentrated in the long-term end of the time bands (that is, for higher $l$ ). Compared to the effects of relaxing the other assumptions discussed above, these ranges seem to be small. However, the effects are large enough to let a non-outlier bank appear as an outlier bank, and vice 


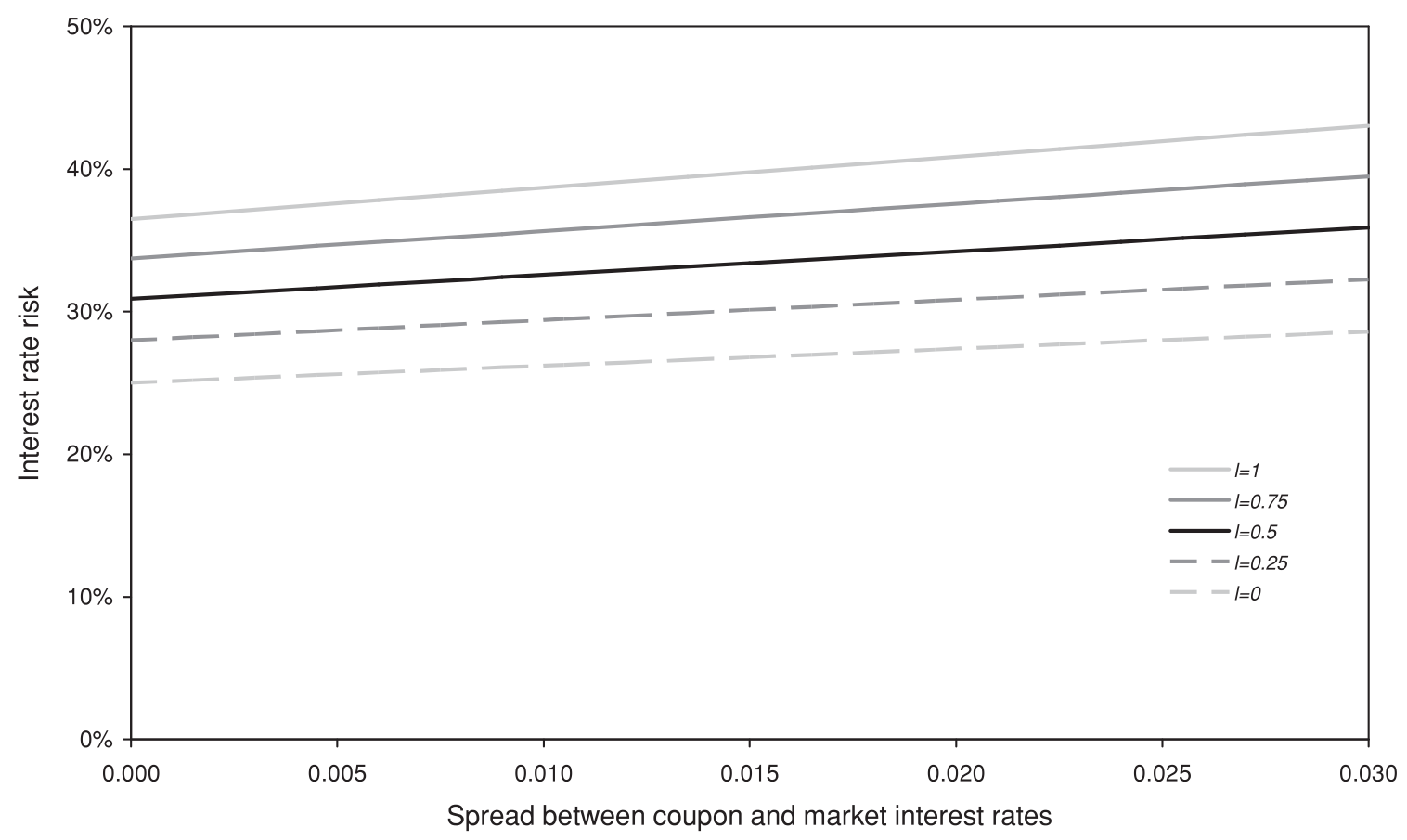

Fig. 4. Impact of the spread between the coupon and the market interest rate.

This figure shows the impact that different assumptions regarding the spread between the coupon and the market interest rate for customer loans and liabilities have on the estimates of the interest rate risk for different location parameters $l$. The location parameter $l$ is defined according to (2). It is not relevant for savings deposits, because a modified duration (here 2.5) is directly assigned to them. The spread is defined as coupon minus market interest rate for customer loans and market interest rate minus coupon for customer liabilities. The market interest rate is kept at $r=5 \%$. The remaining model parameters are specified according to the reference scenario as described in Section 4, i.e., the Basel II time bands are used and the amortisation rate is set to $a=0$.

versa. Furthermore, the coupon payments gain more relevance if banks are considered that have more customer business, relative to their total assets, than the 'average German bank'. This is the case, for example, for average German savings and cooperative banks whose customer-loan-to-total-assets ratio is around $60 \%$, whereas private commercial banks have a ratio of only $41 \%$.

\section{Concluding remarks}

In this paper we analysed the robustness of the standardised framework of the Basel Committee on Banking Supervision (2004b) to assess the interest rate risk of banks. To do so, we generalised the Basel Committee's model by relaxing the critical assumptions and compare the results obtained using the Committee's framework and those of the generalised model in several economically relevant specifications.

Our analysis shows that estimates of the level of interest rate risk change substantially when adjustments are made to the Committee's strict assumptions regarding the distribution of maturities within the time bands, the number and boundaries of the time bands, the amortisation payments or the coupon payments. Even when we stick to the assumptions of the Basel Committee, the estimates can vary considerably, since the Committee allows for a rather broad economic maturity range of non-maturing deposits in the standardised framework. 
For banks with a positive duration gap, the committee's assumption of no premature amortisation of customer business clearly overestimates the interest rate risk of the bank. Ignoring spreads between coupons of customer business and market rates leads to an underestimation. In contrast, the Committee's assumption of a concentration of business in the middle of the time bands can result in a significant bias in either direction. The same holds for the reporting practice, i.e., the number and boundaries of the time bands.

Our analysis has several policy implications. It demonstrates that the standardised framework can misjudge the level of interest rate risk of banks by a considerable amount if a bank's structure differs from the Committee's assumptions. Therefore, estimation results must be treated with caution. Moreover, as the direction of the bias is ex ante unclear for a single bank, the Committee's model does not even provide a conservative estimate; that is, the results cannot be assumed to be always above the 'true' interest rate risk. Therefore, a ranking of banks based on the standardised model-implied interest rate risk is not necessarily consistent with a ranking that is based on the 'true' risk. This also implies that the Committee's model cannot be expected to appropriately distinguish between low-risk and high-risk banks. The latter is of particular relevance as this means that the standardised model cannot reliably identify the outlier banks that supervisors should pay special attention to.

Our results support a central intention by the Basel Committee on Banking Supervision (2004b). Banks should be forced to set up and use comprehensive internal models to quantify their exposure to interest rate changes since a uniformly specified and oversimplified model can lead to large discrepancies between the 'true' and the measured interest rate risk. Of course, this will only work if the internal model is based on bank-individual, reliable and traceable model specifications.

Given the relevance of non-maturing deposits for the (German) banking system and in particular for savings and cooperative banks, it is essential to apply a sound methodology in calculating the exposure of non-maturing deposits to changes in interest rates. Otherwise, banks could use their assumptions regarding non-maturing deposits to arbitrarily reduce their measured interest rate risk.

In any case, supervisors should be sceptical of internal models that are too closely related to the standardised framework. The deliberate use of internal models not only results in a better quantification of the interest rate risk for supervisory purposes, but also motivates many banks to study this very relevant source of risk more deeply and handle it with the necessary care.

If supervisors aim to make their own estimates, they should call for detailed reports of the maturity and repricing structure of a bank's business with much tighter time bands than currently discussed. This would significantly reduce the impact of the necessary assumptions concerning the distribution of maturities within the time bands. Based on this, they could define several 'benchmark models' with different sensible specifications for the remaining relevant parameters. Particularly if large differences between the results of the internal model and these benchmark models occur, a closer look at the specification of the internal model would be in order.

\section{Appendix}

Present value and modified duration

The present value $P V$ of a bond with a face value of 1 , maturity of $T$, a continuously compounded coupon rate $c$ and a continuously compounded amortisation rate $a$ is 
given by

$$
\begin{aligned}
P V & =\int_{0}^{T} c e^{-a t} e^{-r t} d t+\int_{0}^{T} a e^{-a t} e^{-r t} d t+e^{-a T} e^{-r T} \\
& =\int_{0}^{T}(c+a) e^{-(a+r) t} d t+e^{-(a+r) T} \\
& =\left[-\frac{c+a}{r+a} e^{-(a+r) t}\right]_{0}^{T}+e^{-(a+r) T} \\
& =\frac{c+a}{r+a}-\frac{c+a}{r+a} e^{-(a+r) T}+e^{-(a+r) T},
\end{aligned}
$$

where $r$ denotes the continuously compounded market interest rate. If the coupon rate $c$ is equal to the market interest rate $r$, we obtain

$$
\left.P V\right|_{c=r}=\left.\left(\frac{c+a}{r+a}-\frac{c+a}{r+a} e^{-(a+r) T}+e^{-(a+r) T}\right)\right|_{c=r}=1 .
$$

The modified duration $M D$ of the bond is given by

$$
\begin{aligned}
M D & =\frac{-\frac{\partial P V}{\partial r}}{P V} \\
& =\frac{-\left(-\frac{c+a}{(r+a)^{2}}-\left(-\frac{c+a}{(r+a)^{2}} e^{-(a+r) T}+\frac{c+a}{r+a}(-T) e^{-(a+r) T}\right)-T e^{-(a+r) T}\right)}{P V} \\
& =\frac{1}{a+r}+\frac{1+(c-r) T}{c-r-(a+c) e^{(a+r) T}} .
\end{aligned}
$$

For $c=r$, this simplifies to

$$
M D=\frac{1-e^{-(a+r) T}}{a+r} .
$$

\section{References}

Basel Committee on Banking Supervision, International Convergence of Capital Measurement and Capital Standards - A revised framework (Bank for International Settlements, 2004a).

Basel Committee on Banking Supervision, Principles for the Management and Supervision of Interest Rate Risk (Bank for International Settlements, 2004b).

Basel Committee on Banking Supervision, 'Range of practices and issues in economic capital modelling', Consultative Document (Bank for International Settlements, August 2008).

Bennett, D. E., Lundstrom, R. D. and Simonson, D. G., 'Estimating portfolio net worth values and interest rate risk in savings institutions', in Federal Reserve Bank of Chicago, Proceedings - A Conference on Bank Structure and Competition (1986), pp. 323-46.

Bhattacharya, S. and Thakor, A. V., 'Contemporary banking theory', Journal of Financial Intermedition, Vol. 3, 1993, pp. 2-50.

Bundesanstalt für Finanzdienstleistungsaufsicht, 'Zinsänderungsrisiken im Anlagebuch; Ermittlung der Auswirkungen einer plötzlichen und unerwarteten Zinsänderung' (Rundschreiben no. 7/2007, 2007).

Czaja, M.-G., Scholz, H. and Wilkens, M., 'Interest rate risk rewards in stock returns of financial corporations: Evidence from Germany', European Financial Management, forthcoming, 2009a. 
Czaja, M.-G., Scholz, H. and Wilkens, M., 'Interest rate risk of German financial institutions: The impact of level, slope, and curvature of the term structure', Review of Quantitative Finance and Accounting, forthcoming, 2009b.

Deutsche Bundesbank, Financial Stability Review (2006a).

Deutsche Bundesbank, 'The performance of German credit institutions in 2005', Monthly Report, September 2006b, pp. 15-42.

Dewachter, H., Lyrio, M. and Maes, S., 'A multi-factor model for the valuation and risk management of demand deposits' Working Paper no. 83 (National Bank of Belgium, 2006).

Entrop, O., Memmel, C., Wilkens, M. and Zeisler, A., 'Analyzing the interest rate risk of banks using time series of accounting-based data: evidence from Germany', Deutsche Bundesbank Discussion Paper Series 2, no. 01/2008, 2008.

Federal Deposit Insurance Corporation, History of the Eighties - Lessons for the Future (1997).

Houpt, J. V. and Embersit, J. A., 'A method for evaluating interest rate risk in U.S. commercial banks', Federal Reserve Bulletin, August 1991, pp. 625-37.

Hutchison, D. E. and Pennacchi, G. G., 'Measuring rents and interest rate risk in imperfect financial markets: The case of retail bank deposits', Journal of Financial and Quantitative Analysis, Vol. 31, 1996, pp. 399-417.

Jacoby, G. and Roberts, G. S., 'Default- and call-adjusted duration for corporate bonds', Journal of Banking and Finance, Vol. 27, 2003, pp. 2297-2321.

Jarrow, R. A. and van Deventer, D. R., 'The arbitrage-free valuation and hedging of demand deposits and credit card loans', Journal of Banking and Finance, Vol. 22, 1998, pp. 249-72.

Kalkbrener, M. and Willing, J., 'Risk management of non-maturing liabilities', Journal of Banking and Finance, Vol. 28, 2004, pp. 1547-68.

O'Brien, J. M., 'Estimating the value and interest rate risk of interest-bearing transaction deposits', Working Paper (Division of Research and Statistics, Board of Governors, Federal Reserve System, 2000).

Oertmann, P., Rendu, C. and Zimmermann, H., 'Interest rate risk of European Financial Corporations', European Financial Management, Vol. 6, 2000, pp. 459-78.

Office of Thrift Supervision, The OTS Net Portfolio Value Model Manual (2000).

Patnaik, I. and Shah, A., 'Interest rate volatility and risk in Indian banking', Working Paper (IMF no. 04/17, 2004).

Purnanandam, A., 'Interest rate derivatives at commercial banks: an empirical investigation', Journal of Monetary Economics, Vol. 54, 2007, pp. 1769-1808.

Schmidt, R. H., Hackethal, A. and Tyrell, M., 'Disintermediation and the role of banks in Europe: an international comparison', Journal of Financial Intermediation, Vol. 8, 1999, pp. 36-67.

Schmidt, R. H. and Tyrell, M., 'What constitutes a financial system in general and the German financial system in particular?', in Krahnen, J. P. and Schmidt, R. H., eds., The German Financial System (Oxford University Press, 2004), pp. 19-67.

Schrand, C. M., 'The association between stock-price interest rate sensitivity and disclosures about derivative instruments', Accounting Review, Vol. 72, 1997, pp. 87-109.

Sierra, G. E., 'Can an accounting-based duration model effectively measure interest rate sensitivity?', Ph.D. thesis (Washington University in St. Louis, 2004).

Sierra, G. E. and Yeager, T. J., 'What does the Federal Reserve's Economic Value Model tell us about interest rate risk at U.S. community banks?', Federal Reserve Bank of St. Louis Review, Vol. 86, no. 6, 2004, pp. 45-60.

Stone, B. K., 'Systematic interest rate risk in a two-index model of returns', Journal of Financial and Quantitative Analysis, Vol. 9, 1974, pp. 709-21.

Toevs, A. L., 'Gap management: managing interest rate risk in banks and thrifts', Federal Reserve Bank of San Francisco Economic Review, Spring 1982, pp. 20-35.

Wright, D. M. and Houpt, J. V., 'An analysis of commercial bank exposure to interest rate risk', Federal Reserve Bulletin, February 1996, pp. 115-28. 